\title{
Voir ensemble, ouvrage coordonné par Marie José
} Mondzain

Gallimard, coll. « Réfléchir le cinéma », 2003

Cécile de Bary

\section{OpenEdition}

\section{Journals}

Édition électronique

URL : https://journals.openedition.org/ries/1491

DOI : $10.4000 /$ ries. 1491

ISSN : 2261-4265

Éditeur

France Education international

Édition imprimée

Date de publication : 1 décembre 2004

Pagination : $20-21$

ISBN : 978-2-85420-564-0

ISSN : $1254-4590$

\section{Référence électronique}

Cécile de Bary, "Voir ensemble, ouvrage coordonné par Marie José Mondzain », Revue internationale d'éducation de Sèvres [En ligne], 37 | décembre 2004, mis en ligne le 18 novembre 2011, consulté le 05 juillet 2021. URL : http://journals.openedition.org/ries/1491 ; DOI : https://doi.org/10.4000/ries.1491

Ce document a été généré automatiquement le 5 juillet 2021.

(c) Tous droits réservés 


\title{
Voir ensemble, ouvrage coordonné par Marie José Mondzain
}

\author{
Gallimard, coll. « Réfléchir le cinéma », 2003
}

\section{Cécile de Bary}

\section{RÉFÉRENCE}

Voir ensemble, ouvrage coordonné par Marie José Mondzain, Gallimard, coll. « Réfléchir le cinéma », 2003

1 Voir ensemble est un ouvrage placé sous le signe du multiple. Il émane tout d'abord d'une association, le "groupe de réflexion sur le cinéma » nommé l'Exception. De plus, comme le dit sa couverture, ce livre rassemble «douze voix » autour d'un thème qui concerne encore le commun et le divers, « Voir ensemble ».

2 Ce thème, c'est celui d'une conférence donnée par Jean-Toussaint Desanti à l'invitation de Marie José Mondzain. La conférence, prononcée à l'École des Beaux-Arts de Paris le 11 juin 2001 dans le cadre de l'observatoire de l'image (Obi), est reproduite au début du livre. Devant cet auditoire, Jean-Toussaint Desanti s'est intéressé aux implications esthétiques de l'expression "Voir ensemble». Cependant, Marie-José Mondzain le rappelle en préface, cette conférence implique un soubassement éthique. Et ce qui frappe en première lecture, c'est que le raisonnement de Desanti, apparemment simple et tout à fait accessible, est essentiellement phénoménologique.

De fait, ce philosophe né en 1914 a été marqué par la rencontre de Maurice MerleauPonty, dans les années trente. Constitué autour d'une des dernières conférences de Desanti, décédé en janvier 2002, ce livre-hommage peut permettre de découvrir un auteur majeur, trop rare. On peut y retrouver sa biographie, accompagnée d'une bibliographie. Y est aussi reproduit un article paru dans le Symposium de l'Encyclopcedia Universalis de 1984 - «Sur la crise » -, texte qui éclaire la conférence de 2001.

4 D'abord professeur, en lycée, à l'École normale, à l'université de Paris-I, Jean-Toussaint Desanti a été marqué dans son itinéraire par l'histoire de ce siècle. Engagé auprès du 
Parti communiste au moment de l'Occupation, il a jusque dans le milieu des années cinquante participé d'un aveuglement collectif, ce qui explique et éclaire sa réflexion. S'il fut familier de peintres comme Picasso, il est moins connu pour ses réflexions concernant la perception ou l'esthétique que pour des travaux d'épistémologie des mathématiques.

Dans cette conférence, il interroge les possibilités de la vision, comme celles de la constitution d'une communauté. Toute visibilité implique de l'invisible. Quant à la multiplicité des points de vue - des «sites»-, elle ne peut se résoudre que par une construction dans le dialogue, dans la parole: Desanti se méfie de tout sentiment artificiel d'identité collective. "Nous ne voit rien", dit-il. Il aborde aussi la mise ensemble de toutes les facettes de l'objet par l'artiste, dans un espace autre.

"Sur la crise» complète cette conférence apparemment sereine en dévoilant l'inquiétude qui sous-tend sa réflexion. Ce texte permet également de lui restituer sa dimension politique. "Nous parlons du monde en disant "notre monde" ", comme s'il était un. D'une certaine façon, il l'est. D'une manière visible et quasi charnelle : pour la première fois, depuis que l'humanité existe, certains hommes ont vu la Terre de loin, toute ronde, en totalité. Et nous-mêmes en nos fauteuils la voyons, certains soirs, telle que la photographient les satellites. Petite image qui contient toute l'humanité vivante (et notre fauteuil aussi). Cette situation demande réflexion, car j'y vois comme l'expression symbolique des maladies les plus graves dont nous souffrons.» (pp. 261-262.)

7 Reste que l'ouvrage est constitué pour l'essentiel par d'autres voix, qui accompagnent celle de Desanti. Autour de Marie José Mondzain, autour de Jean-Michel Frodon, directeur de la rédaction des Cahiers du Cinéma et fondateur de L'Exception, douze voix sont donc rassemblées, dans le cadre de trois entretiens.

8 Le premier, où ces deux auteurs discutent avec les philosophes Myriam Revault d'Allonnes et Patrice Loraux, permet d'éclairer la pensée de Desanti dans ses implications comme dans l'intertexte qu'il convoque. À l'aide de leurs références, de leurs témoignages, de leurs interrogations, les interlocuteurs parviennent à faire saisir l'originalité de la pensée de Jean-Toussaint Desanti, jusque dans ses apories, son refus de conclure : comme la nuque échappe au regard de qui voit un front, le réel échappe toujours au discours.

9 Le deuxième entretien rassemble, autour des mêmes quatre interlocuteurs, trois cinéastes : Benoît Jacquot, Nicolas Philibert et Olivier Assayas. Le dialogue devient ainsi l'occasion pour des non-philosophes de se saisir d'un texte philosophique. De dire en quoi il les concerne et de dire comment la question du «voir ensemble» se pose pour eux, dans leur pratique. De fait, comme le rappelle Jean-Michel Frodon en postface, le cinéma est « le plus collectif des arts », dans sa fabrication comme dans sa réception. Et dans ce dialogue, Olivier Assayas rappelle également comment le montage est mise ensemble, dans la construction - ou non - d'un " voir ». Dans cet échange, c'est de fait la question de l'invisibilité qui est centrale.

10 La dernière conférence rassemble Marie José Mondzain, les hommes de théâtre Alain Françon et Robert Cantarella, le cinéaste Jean-Louis Comolli et le plasticien Ernest Pignon-Ernest. Dans cet ensemble, la voix discordante de Catherine Dolto, médecin haptonomiste, rappelle avec insistance l'importance du sensible, jusque parfois dans un certain oubli du symbolique et du langage, comme Marie José Mondzain le lui fait remarquer. Ce dialogue est avant tout l'occasion pour des artistes de présenter leur 
travail, dans la perspective donnée par Jean-Toussaint Desanti. Ainsi du projet d'Ernest Pignon-Ernest en Afrique du Sud, qui surgit à l'occasion d'une rencontre, avec des malades et des acteurs de la lutte contre le Sida. Ou de l'enquête de Jean-Louis Comolli, qui l'a conduit à «filmer l'ennemi », l'électeur du FN.

11 Toutes ces voix, ensemble, dans leur diversité, suscitent donc chez le lecteur une réflexion personnelle, tant esthétique qu'éthique ou politique, en hommage à ce pédagogue que fut l'auteur de « Voir ensemble».

\section{AUTEURS}

CÉCILE DE BARY

Université de Nice. 